\title{
Mother Love and Mental Illness: An Emotional History
}

\section{Citation}

Harrington, Anne. 2016. "Mother Love and Mental Illness: An Emotional History." Osiris 31 (1) (July): 94-115. doi:10.1086/687559.

\section{Published Version}

$10.1086 / 687559$

\section{Permanent link}

http://nrs.harvard.edu/urn-3:HUL.InstRepos:33439059

\section{Terms of Use}

This article was downloaded from Harvard University's DASH repository, and is made available under the terms and conditions applicable to Open Access Policy Articles, as set forth at http:// nrs.harvard.edu/urn-3:HUL.InstRepos:dash.current.terms-of-use\#OAP

\section{Share Your Story}

The Harvard community has made this article openly available.

Please share how this access benefits you. Submit a story.

\section{Accessibility}




\title{
Mother Love and Mental Illness:
}

\section{An Emotional History}

\author{
By Anne Harrington*
}

\begin{abstract}
:
This essay aims to illuminate the historical origins of psychiatric concern with mother love - and especially mother love gone wrong. It looks particularly at ways in which a combination of wartime research, postwar social concerns and new tensions between psychoanalysis and hospital psychiatry worked together to create a range of theories and practices predicated on the idea that specific forms of pathological mother love could lead to specific forms of mental disorder, including (and perhaps especially) schizophrenia. It also tells the story of how mothers of the schizophrenic patients in particular rose up - in the name of love to challenge the view that they had caused their children's illness, and why this happened.
\end{abstract}

"The mother-child relationship is so important for ensuing pathology that it has probably received more attention than any other aspect of child psychiatry" (Franz Alexander and Sheldon Selesnick, The History of Psychiatry: An Evaluation of Psychiatric Thought and Practice from Prehistoric Times to the Present, 1966)

"We failed to understand why parents of a child with leukemia were treated with sympathy and 
understanding, while parents of a child with schizophrenia were treated with scorn and condemnation." (Eve Oliphant, mother of an adult son with schizophrenia, addressing the American Psychiatric Association, 1977)

In May, 2010, a documentary aired on various public television stations across the United States. It told a story about an effort by courageous families to challenge and eventually overthrow a pernicious doctrine that had taken hold of American psychiatry from the 1940s through the 1970s: a doctrine that said that schizophrenia, the most serious and tragic of mental disorders, is caused by bad parents, and especially by bad mothers. May was chosen as the month for multiple broadcasts of the documentary -- in honor of Mother's Day. And the takehome message of the documentary was clearly summed up in its title: "When Medicine Got it Wrong."

It is easy to agree that medicine got it wrong in this case, but we do not help ourselves much by simply seeing this chapter as a wrong-headed and rather unpleasant example of a general tendency among presumptively misogynist clinicians of the 1950s to blame mothers for everything. Yes, we wince at the kinds of things that people, as recently as 25 years ago, told mothers. We are appalled at therapists who insisted that some mothers, literally, drive their children psychotic. Nevertheless, as we consider this most emotional of chapters in the recent history of psychiatry, we also have an opportunity to move beyond mere condemnation, and try instead to understand.

Undergirding the more specific story I want to tell here is a larger story about cultural 
shifts in the consensus about what desirable or ideal styles of motherhood more generally. More specifically, the 1920 s began to see a growing resistance within American society to a style of Victorian-era mothering that some have called "moral motherhood." This style of motherhood had been marked, among other things, by a "tight, indeed controlling bond" between the mother and her (usually) male child. The bond was supposed to be for his own good: it would act as a moral rudder that would guide the adult man through his life.

By the 1920s, however, emotional involvement of this sort was increasingly believed to set the child up for a life of dependency and immaturity - or worse. A new breed of Progressive-era experts began to lay out the conditions for what they saw as a more rational and scientifically-grounded approach to child-rearing - one marked by schedules, authorized childcare products, and continued medical advice. Mothers who were judged to be too permissive, too affectionate, and too casual in their approach came in for increasing censure.

During and especially after World II, we see a shift again. The prewar ideal of the modern "scientific" mother began to give way to a vision of the ideal mother as someone who was naturally affectionate and available to her child, albeit without, stifling his or her emotional growth. In other words, this "naturally" loving mother was there now, less as a moral rudder for her son, and more to give him the emotional security he needed to eventually be able to stand on his own two feet.

The story of these changing ideals of motherhood and mother love has been persuasively told by other scholars. What we sometimes lack in their accounts, however, is a more granular understanding of the specific ways in which each of these shifting ideals created its antithesis, its 
shadow. As both an historical strand in $20^{\text {th }}$-century medical thinking about emotions and mental health, and as a chapter in the emotional life of ordinary people in the United States and beyond, the story of how mental illness in general, and schizophrenia in particular, became a disorder of maternal love gone wrong is ripe for serious historical scrutiny.

\section{Beyond Freudian Fathers: The Turn to Mother Love}

We might imagine that the story begins with misogynistic men, but it is not so. In fact, many of the deepest roots of clinical interest in mother love - adequate, and pathological - lies with influential female psychoanalysts: people like Melanie Klein, Anna Freud, Helene Deutsch and Karen Horney. Their agenda was not misogynist: on the contrary, it was marked by a distinctly pro-woman and pro-mother sensibility.

Classical Freudian theory had sometimes seemed to suggest that the only reason women might want to be mothers would be to compensate for the feelings of inferiority that resulted from not having a penis ("penis envy"). In the 1920s, a new generation of women analysts began

to speak up and insist that this was nonsense. The experience of motherhood, they argued, was a fundamental and - for the most part - emphatically positive dimension of female psychology,; one that should be understood on its own terms, as being marked by powerful emotions distinct from sexual love. "Its chief characteristic," Helene Deutsch insisted, "is tenderness." This was not to say that motherhood was always easy or without pain, as Deutsch also underscored: "[T]here is hardly a woman in whom the normal psychic conflicts do not result in a pathological distortion, at some point, of the biologic process of motherhood" But that was all the more 
reason, these women analysts insisted, for psychoanalysis as both science and clinical practice to take mother love seriously as a critical part of female psychology.

What about the kids on the receiving end of this love? Classical Freudian psychoanalysis had also sometimes implied that the mother- child relationship was just a rather uninteresting prelude to the great Oedipal drama focused on the father, when all the important developmental issues were worked out. This is because, for most of his career, Freud had portrayed mothers rather instrumentally, as simply means for satisfying the physiological needs of infants for food, warmth, and safety. Only at the very end of his career did Freud consider that the mother-infant relationship might be psychologically critical as an end in itself (he thought perhaps especially for girls). But even as he tried out this (to him) new idea, he confessed himself personally unable to follow through on all of its implications: "Our insight into this early, pre-Oedipus phase in girls come to us as a surprise, like the discovery, in another field, of the Minoan-Myceanean civilization behind the civilization of Greece."

It fell to others, therefore, to clarify ways in which the maternal relationship mattered -and actually mattered most -- for the emotional development of both girls and boys. The initiative here was undertaken in particular by a new generation of analysts, who came of age in the 1930s, and helped spearhead a series of major revisions of psychoanalytic theory in Europe and the United States (ego psychology, object relations theory). While the rise of both ego psychology and object relations theory was a complicated affair, for our purposes the most important thing to know about it was that (in contrast to classical psychoanalysis) it gave great weight to the emotional effects of experiences that happened in the first years and even months of life. In so doing, it also turned attention away from imaginary castrating fathers and towards 
the role of early maternal care. At the same time, it downplayed classical Freudian concerns with infantile biological drives and focused more on ways in which an infant is shaped by its early experience within the family, especially through interactions with the mother. Donald Winnicott, one of the British architects of object relations theory in the 1930 s, went so far as to say in 1940, "There is no such thing as an infant... whenever one finds an infant one finds maternal care, and without maternal care there would be no infant."

\section{Life Without a Mother's Love}

Significantly, many of the clinicians who came to this conclusion did so against a backdrop of extensive direct work with young children in hospitals, clinics, or nurseries. And it happened that, during World War II, many of them also directly witnessed the bad things that can happen to young children when their mothers aren't around to love them.

Some of them witnessed what happened in England, for example, when many babies and young children were sent away from London (to avoid the bombings, because they had become orphaned, or because both parents were working). Living in special institutions where they all received adequate physical care, they nevertheless regressed developmentally, and showed other signs of emotional dysfunction. Without their families, and especially without the love of their mothers, their emotional and cognitive development was threatened. Freud's daughter, Anna (having moved with her father to England to escape the Nazis), was key in identifying these and other signs of what would become known as "maternal deprivation." Working with her companion Dorothy Burlingham at a war nursery set up in Hampstead, in north London, she observed how, by six months, the infant's need for a mother's affection is "as urgent for his psychological satisfaction as the need to be fed and taken care of is for his bodily comfort." And 
by the second year of life, the child responds to separation from the mother with all the signs of deep grief and distress.

Meanwhile, in the United States, the Viennese Hungarian émigré Rene Spitz had been studying children who were separated from their mothers, not because of war, but because they were orphaned or required hospitalization for a prolonged period. He found that they didn't just regress cognitively and emotionally: they also sometimes physically wasted away and died. Spitz called this syndrome "marasmus" or (when caused by hospitalization) "hospitalism." His most influential work on this front compared the outcomes for infants being raised in two institutions: one (a prison nursery) in which they could interact with their own mothers, and one (a home for foundlings) in which they were cared for impersonally by nursing staff. Here is what happened: While the children in the "Nursery" [where they could interact with their own mothers] developed into normal healthy toddlers, a two-year observation of "Foundling Home" [where they were cared for by "overworked nursing personnel"] showed that the emotionally starved children never learned to speak, to walk, to feed themselves. With one or two exceptions in a total of 91 children, those who survived were human wrecks, who behaved either in the manner of agitated or apathetic idiots.

The most impressive evidence probably is a comparison of the mortality rates of the two institutions. "Nursery" in this respect has an outstanding record, far better than the average in the country. In a five years observation, during which we observed a total of 239 children, each for one year or more, "Nursery" did not lose a single child to death. In "Foundling Home," on the other hand, 37 percent of the children died during a two years' 
observation period.

At the end of World War II, Ronald Hargreaves of the World Health Organization (WHO) commissioned the child psychiatrist John Bowlby, then head of the Department for Children and Parents at the Tavistock Clinic in London, to write a report on the mental health of displaced, orphaned, and refugee children in postwar Europe, and make recommendations. Informed by his own previous work on "affectionless youth," and drawing on the insights of Anna Freud, Rene Spitz, and others (such as Bill Goldfarb in the United States), Bowlby's 1951 Maternal Care and Mental Health was immediately recognized as a landmark synthesis of prevailing knowledge on this subject. More than any other document of the time, this book sealed the case that mother love was the foundation for the making of any kind of viable emotional self.

What is believed to be essential for mental health is that the infant and young child should experience a warm, intimate and continuous relationship with his mother (or permanent mother-substitute) in which both find satisfaction and enjoyment... Prolonged deprivation of a young child of maternal care may have grave and far reaching effects on his character ... similar in form... to the deprivation of vitamins in infancy.

\section{Mother Love Appraised: The Role of Child Guidance Clinics}

Children needed a mother's love, then; but were all forms of love equally beneficial? Even before World War II, mental health workers in child guidance clinics in the United States and England had been clear that they were not. We hardly know anymore what child guidance clinics were, but in the first decades of the 20th-century, they were important new outposts of psychiatry's outreach efforts. Their origins lay, not so much directly in psychoanalytic re- 
evalutions of the role of mother love, but in Progressive-era efforts to apply a public-health early-intervention sensibility (often called "mental hygiene") to the problem of mental disorder. Critical of older mainstream approaches that basically saw most or all of the mentally ill as incurable victims of tainted biology, child guidance clinics were instead committed to the meliorist view that, by intervening early in the lives of troubled (and troublesome) children, it might be possible both to reduce juvenile delinquency and to forestall future instances of adult mental pathology. As the American psychiatrist Frankwood Williams put it in 1923:

Individuals are not born odd, or queer, or peculiar. Timid, sensitive, blustering, rebellious children are not born, they are made - and made by quite human agencies.... Children born well who later contract tuberculosis of the spine or infantile paralysis come eventually to plaster casts or braces from which after a time they are relieved, many improved and helped; but children born well who later contract certain habits of emotional reaction come eventually to courts and reformatories from which after a time they are relieved, few of them improved or helped. ... [Some] are to fail entirely. ... [and] within fifteen years [are] gathered to their mattresses on the floors of hospitals for the insane.

Through the 1920s, as scholars like Kathleen Jones have shown, the focus of these clinics was on instructing poor and uneducated immigrant families in good hygiene, nutrition, and scientifically-validated, modern methods of childrearing. By the 1930s, though, these clinics were serving middle-class families, who brought in children with problems ranging from bedwetting to truancy to stuttering. They had also begun to engage with the new psychoanalytic 
ideas about the centrality of mother love to healthy child development discussed in the previous sections of this essay. Adapting Freudian thinking to their own purposes, they came to assume that all of these childhood troubles had their roots in troubled family circumstances, and especially in the emotional problems of mothers. In one way or another, the argument went, the mothers were all failing to love and nurture their children in ways that would vouchsafe their healthy emotional growth.

What had gone wrong? The most common diagnosis of these mothers was reasonably sympathetic: women who produced troubled children tended themselves to be deeply unhappy with their lives and marriages. Some, it was felt, also suffered from what was called "primary affect hunger," resulting from having failed to experience adequate love in their own childhoods. While some of these deprived mothers responded by emotionally rejecting their children, most were seen as compensating for the emotional poverty of their own lives by becoming "overprotective" and emotionally over-involved with their offspring.

To help the children, it was concluded, the child guidance centers had to find a way to help the mothers too. Thus it came that, in many instances, the mother would be offered an opportunity to undergo psychotherapy with a (female) social worker, while a psychiatrist would focus on treating the child. Sometimes, the mothers would agree to do this, and sometimes they would not. The stakes were high, but they remained a reasonably private matter, something that was to be negotiated between the social workers, the psychiatrists, the mothers, and the children. 


\section{Sissies, Homosexuals, Racists, and Delinquents: The Heightened Postwar Stakes}

After World War II, however, the stakes were raised, and the whole problem of deficient mothers and troubled children became a much more public - and a much more political -conversation. To understand why, it is important to realize the degree to which, in the immediate postwar years, a new generation of American and European social scientists had successfully defined virtually all the big social problems of the day, not as problems of public policy or institutional failure, but as problems of individual psychology - of emotional inadequacy. If the United States failed to win the Cold War, if the country succumbed to Communism, if the black man failed to advance himself socially, if boys were seduced into homosexual lifestyles, if girls failed to protect their sexual virtue, and if cities were terrified by lawless youth gangs, the fault lay in the brittle or warped personality structures of all the individuals involved.

None of these individuals had been born bad or defective, the experts continued. Their personalities, for better or worse, had been shaped by their family circumstances, by the neighborhoods in which they had grown up, and above all by the ways in which they had been loved and cared for by their mothers. As we have seen, this belief in the environmental roots of deviance and mental disorder had functioned in the 1930s child guidance clinics as a progressive and rather hopeful doctrine (since what had been made could presumably be unmade). In the postwar era, however, it took an increasingly punitive and accusatory edge. To a first approximation, the failures of the mothers to love their children in the right way came to be seen as the witting or unwitting pernicious force behind virtually every form of deviant citizenship 
with society.

Consider, by way of example, the discussion of this time about a problem of great national concern: psychiatric breakdown during the recent world war. During the war, 1,825,000 young men had been preemptively rejected from service on "neuropsychiatric" grounds. Nevertheless, close to 1 million others broke down mentally during the war itself, sometimes even before they saw combat, or under circumstances that did not seem excessively adverse. What was wrong with America's young men? Why were they so weak, immature, and unstable?

In 1945, Dr. Edward Strecker, a former President of the American Psychiatric Association and a psychiatrist who served as a special consultant to the Secretary of War and the Surgeon General of the Army and Navy, answered this question with a description of a certain sort of inadequate mother that he called a "mom" (picking up a term employed to great effect by the freelance author Philip Wylie in his 1942 A Generation of Vipers). Although "moms" came in a number of shapes and sizes (the "self-sacrificing," the "ailing," the "pollyanna," the "protective," the "pretty addlepate" and the "pseudointellectual"), all of them shared one critical attribute: they had all "failed in the elementary mother function of weaning her offsprings emotionally as well as physically." As a result, Strecker argued, these moms were more responsible than anything else for the "epidemic" of psychoneurosis that had been revealed in the recent world war. Their selfish immaturity could have lost the United States its victory in that war, Strecker said, and it was now threatening the capacity of the country to defend itself against new enemies. For this reason, he concluded, these "moms" must be recognized as "our gravest menace, a "threat to our survival" as a democratic civilization.

Strecker's attack on moms was no marginal affair. He first made his case in a 1945 
lecture to medical colleagues, which was reported in the New York Times. A print version of the argument appeared several months later in the psychiatric journal Mental Hygiene, under the title "Psychiatry Speaks to Democracy"). A book expanding the argument, Their Mothers'Sons, was then published in 1946 to extensive press coverage. The argument was also widely discussed or reported in the popular press: pieces appeared in The Ladies' Home Journal (“Are American Moms a Menace?"), the Saturday Evening Post ("What's Wrong with American Mothers"), Time ("Mama's Boys") and the Washington Post ("Momism"). Many were persuaded that the issue at hand was no joke: "Mom is bad for the son and, therefore, bad for the country," agreed one military-minded reviewer of Strecker's book in 1947. It was good that Strecker was giving this matter the public airing it deserved.

Strecker's attack on clinging, narcissistic mothers in part attracted so much attention because it tapped into a more general debate in this time about an alleged "crisis of masculinity." It was, however, only one critique among many in these years. As the larger vision of ideal motherhood shifted generally away from the rational and scientific of the interwar period and toward a more instinctual, nurturing ideal, other critics drew attention to the effects on children and society of neglectful and permissive mothers, rejecting mothers, seductive mothers, domineering mothers, ambivalent mothers, and more. These mothers were variously deemed responsible for creating deviant citizens ranging from racists to juvenile delinquents to homosexuals. While most of the mothers who came under scrutiny were implicitly white and middle-class, some analysts also trained their attention on the deficiencies of black mothers and the effects they were having on the psyches of their children, especially their sons. At the same 
time, some anthropologists looked outside the American context and examined the allegedly rigid and undemocratic childrearing traditions of Japanese and German mothers for clues into the root sources of the national characters of America's recent enemies. There were many kinds of mothers that people in these years worried about.

\section{Mother Love and Schizophrenia: A Conversation Apart}

In these years, however, one of these deficient mothers stood out from all of the others. This was a mother who literally drove her child crazy - made him psychotic, made him schizophrenic. Not only did the conversation about this mother and the effects she had on her child represent the most extreme edge of the larger territory of psychoanalytic discussions about the effects of inadequate or perverse mother love on emotional development. It was also the only conversation that was mounted as a deliberate challenge to professional rivals within psychiatry: rivals with a very different understanding of the disorder.

Since the late $19^{\text {th }}$-century, there had been a general consensus, at least within hospital psychiatry, that schizophrenia (or its predecessor, dementia praecox) was a brain disorder. Characterized by a disruption of the ability to connect ideas together coherently, as well as hallucinations and (often) profound feelings of terror and paranoia, schizophrenia was also widely believed to be a degenerative, incurable condition. Some clinicians had sought its origins in structural abnormalities of the brain (that could be made visible through microscopic research). Others had favored metabolic theories, which conceived the disorder as a form of auto-intoxication or infection, caused by toxins produced in other parts of the body, especially the sex glands, the intestines and the mouth. Still others had focused on evidence suggesting a 
hereditary basis for the disorder.

All this matters. When psychoanalytically-inclined clinicians and social scientists made claims in these same years about the maternal roots of juvenile delinquency, racism, military unpreparedness, and even sexual deviance, they were met with skepticism on various fronts, but very few of their critics insisted that the roots of these conditions should instead be sought in the brain. The story of schizophrenia and mother love was different. It was animated by all of the other wartime and immediate postwar concern with mothers, but it was targeted first and foremost at all the critics who wanted to insist that bad brains, not bad mothers were responsible for schizophrenia.

The problem with this approach to schizophrenia, according to the psychoanalyticallyinclined clinicians, was not just that decades of efforts to find the brain lesion, source of infection, or hereditary basis of the disorder had so far failed (as even those who supported the effort had to admit). It was also that the approach was so dehumanizing. It had the effect (in the critical words of Carl Gustav Jung) of turning the patient into "a cerebral machine thrown out of gear. "In fact, these clinicians insisted, schizophrenics were human beings who suffered from human problems, and needed to be embraced again as such. In Jung's words:

Hitherto we thought that the insane patient revealed nothing to us by his symptoms save the senseless products of his disordered cerebral cells; but that was academic wisdom reeking of the study. When we penetrate into the human secrets of our patients, we 
recognize mental disease to be an unusual reaction to emotional problems which are in no way foreign to ourselves...."

If this was so, did it follow that some schizophrenic patients might benefit from psychoanalytic psychotherapy -- that it was not incurable after all? Freud himself had cautioned against drawing that conclusion; he believed that psychotic patients were too regressed to be able to establish a viable therapeutic relationship with a clinician. Others, though, were not prepared to give up so quickly. By the 1940s, a small number of people in Europe and the United States -Marguerite Sechehaye, Lilly Hajdu-Gimes and Sandor Ferenzci, Gertrude Schwing, Frieda Fromm-Reichmann, John Rosen - began to adapt psychoanalytic psychotherapy into forms that might be suitable as a treatment for schizophrenia.

The stakes were raised in this conversation by the fact that the 1930s had actually seen the widespread introduction of several new somatic treatments for schizophrenia and other serious mental disorders: ECT, insulin coma therapy, and later lobotomies (drugs were not until the 1950s). No one really knew why or how well these treatments worked, but many in the hospital system were convinced that they helped, and in the eyes of many, they bolstered the case that schizophrenia was a brain disorder not a disorder of nurture, even if the nature of the brain disorder was not yet clear. The analysts countered that the somatic treatments were brutal, and that they worked -- if they worked at all -- only by dulling the symptoms without genuinely getting to the sources of the problem. As Frieda Fromm-Reichmann said during a clinical case conference in the early 1940s, where staff were considering using insulin, barbiturates or Benzedrine on an unruly patient: "Do you want to knock him out completely or give him enough 
to relax and then be able to talk to you as he comes out of it? .... It seems to me you should give [the medicine] but not deprive him of his doctor."

Eager to promote an alternative therapeutic path for patients like this, certain therapists began to suggest instead that schizophrenia might be best seen as a psychological rather than a biological disorder: an emotional response to severe trauma or a deprived childhood. Of course the mothers must therefore have been central in whatever infantile trauma might lie behind the disease, but initially their focus was less on what the patients' mothers had done wrong and more on what they, as therapists, might do to set things right. It is striking how many of the therapists who forged this alternative therapeutic path were themselves women, offering themselves (implicitly, and on occasion explicitly) as the "good mother" that their patients never had.

In the 1940s, the Swiss therapist Marguerite Sechehaye went so far as to encourage her young adolescent patient to call her "Mama", physically cradled her as if she were a baby, and talked to her as if she were a tiny child. At one point in the therapy, Sechehaye even went so far as to symbolically breastfeed the girl, when it emerged that her desperate pleas for "apples" were really a cry for a loving maternal breast. In Sechehaye's words:

I grope about in the beginning, not knowing how to calm this need for apples. I bring Renee beautiful apples, the most beautiful I can find, and pounds of them, telling the landlady to give Renee as many as she desires. But Renee always refuses them... Renee runs away and arrives at my house all alone, at nine in the evening, in terrible agony. I persist in trying to understand the symbolism of the apples. To the remark that I gave her as many apples as she wanted, Renee cries: "Yes, but those are store apples, apples for 
big people, but I want apples from Mummy, like that," pointing to my breasts. "Those apples there Mummy gives them only when one is hungry." I understand at last what is to be done! Since the apples represent maternal milk, I must give them to her like a mother feeding her baby: I must give her the symbol myself, directly and without intermediary.

Insight having dawned, Sechehaye sliced an apple, and invited her patient to lay her head on her breast and "drink the good milk." The girl did so, while slowly eating the apple, finally at peace.

In a somewhat different register, Frieda Fromm-Reichmann, a refugee from Hitler's

Germany now living in the United States, became renowned, even at the time, for her willingness to do whatever it took to make an emotional connection to her severely disturbed patients, all of whom she believed had been rejected by their mothers. She would sit in their urine to show them that she was not better than they were. She would accept a gift of feces from them to show them that she was not rejecting them. In the admiring words of one of her colleagues:

Sooner or later the schizophrenic patient experienced that he was no longer alone, that here was human being who understood, who did not turn away in estrangement or disgust. This rare moment of discovery - unpredictable and unforeseen, like a gift of grace - sometimes became a turning point in the patient's life. The gates of human fellowship were opened - and thereby the slow way to recovery was opened also."

Mother Love and Schizophrenia: The Worst Mother of All? 
While it is very likely that clinicians who advocated a psychotherapeutic approach to schizophrenia had speculated from the beginning about what the real mothers of their patients were like, it was not until the 1940s - when highly politicized concerns about bad mothers and matriarchal families were common fare - that the question seemed to matter enough to warrant a public airing. Fromm-Reichmann set the terms of the conversation to come in 1940, when she rather casually coined the memorable term "schizophrenogenic mother" in the course of a discussion about research on the role of mothers in family groups. At that time, influenced by sociological work undertaken by fellow refugees on the "authoritarian family," she related schizophrenia to authoritarian parenting, and suggested that in the United States (in contrast to Europe) children fear their "domineering mother" rather than their father. Trude Tietze, another woman refugee immigrant from Vienna, subsequently reinforced this particular profile in a widely-cited 1948 article called simply "A study of mothers of schizophrenic patients." Tietze's data supported, she believed, the following conclusions: "Rejection of the child, dominance, overanxiousness, obsessiveness, perfectionism, and oversolicitousness were common personality characteristics of these mothers."

By 1948, influenced by the tendency of new American colleagues like Clara Thompson and Harry Stack Sullivan to find the roots of schizophrenia in disturbed interpersonal relations, Fromm-Reichmann began to focus less on maternal authoritarianism and more on the presumed rejection and lack of love to which she believed these mothers subjected their children:

The schizophrenic is painfully distrustful and resentful of other people, due to the severe early warp and rejection he encountered in important people of his infancy and 
childhood, as a rule, mainly in a schizophrenogenic mother. During his early fight for emotional survival, he begins to develop the great interpersonal sensitivity which remains his for the rest of his life.

Throughout the 1950s, the schizophrenogenic mother was sometimes described as rejecting, sometimes as domineering, and sometimes as both. One 1957 study, run out of a Veteran's Hospital, used the so-called F-scale test ("F" for "fascism") to test the personality traits of a group of mothers of (male) schizophrenic patients, and found evidence that they scored higher than the control mothers. On the other side, John Rosen, one of the more flamboyant but influential analysts offering psychotherapy to schizophrenic patients, spoke of the "poisoning" of the child's early emotional development caused by a "perverse mother" who (perhaps through no fault of her own) lacked the ability to give the infant child the love and security he or she needed.

By the 1960s, though, enough studies were failing to find any consistent pattern of dysfunction among these mothers that the entire effort began to lose credibility. A new approach was needed, which retained the therapeutic commitment to the patient not as a broken machine, but as a victim of humanly comprehensible trauma. Clinicians found one by broadening their gaze. Instead of just focusing on the mother and her distorted emotional relationship to her child, they began to look at the whole family as a system, and tried to understand ways in which pathological behavior and especially pathological communication within a family might produce schizophrenia.

The new systems approach was supposedly committed to a neutral moral attitude towards 
the family of the schizophrenic: people acted the ways they did because of the role they had in the system, and it was the system that was broken, not necessarily the people in it. Nevertheless, in practice, attitudes towards these families remained highly condemnatory. Speaking at a symposium in 1962, one clinician put the matter this way:

The family of the schizophrenic patient does violence to our implicit attachment to 18 th century liberal rationalism; that is, they challenge our need for explicit meaning, as well as our liberal optimism about the strength of inherent growth motives, the salutory effects of benign impartial intervention, the motivational basis of our need to help people, and the value of exclusively verbal statements and logical explanation. This is probably one reason why existentialism, phenomenology, and other forms of subjective philosophy have become so intimately related to thinking about schizophrenia. These families can confound our rational theories, dispel optimistic planfulness, and plunge us into ... therapeutic despair ....

Jay Haley, an influential founder of so-called family therapy, concurred:

The greatest challenge to any family therapist is the psychotic family. Whatever difficulties there are in neurotic families, they are exaggerated to the point of parody in the family of the schizophrenic. Various approaches have been used and schools established to deal with these families, from valiant therapists singly assaulting the schizophrenic family citadel to expeditions in twos and threes. An attempt was even made to surround the whole family with a hospital.

By the late 1960s, the Scottish radical psychiatrist Ronald Laing became famous for 
pushing the conversation about families and mental illness beyond the now familiar argument that bad mothers and bad families can cause schizophrenia (which he vigorously believed). He proposed that actually the families who successfully produce the bourgeois, one-dimensional children that our society calls "normal" were just as perverse and culpable as the families who turn their children into a state of psychosis:

The ["normal"] family's function is to repress Eros; to induce a false consciousness of security; to deny death by avoiding life; to cut off transcendence; to believe in God, not to experience the Void; to create, in short, one-dimensional man; to promote respect, conformity, obedience; to con children out of play; to induce a fear of failure; to promote respect for work; to promote respect for "respectability

\section{Mother Love and the End of the Schizophrenogenic Mother}

Then, in the late 1970s, all of this finally began to unravel. The conventional explanation for why this is that, just when things were getting completely ridiculous, psychiatry rediscovered the brain and biology. A slew of new research, along with effective new biological treatments (drugs), put the psychotherapists and their ungrounded ideas out of business.

Advocates of this explanation often cite Seymour Kety's adoption studies in the early 1970s, which showed, among other things, that children born to a schizophrenic mother and reared in an adoptive family become schizophrenic at the same rate as siblings reared by their biological schizophrenic mother. This seemed definitively to demonstrate a hereditary basis for schizophrenia. One of Kety's colleagues and admirers was unequivocal: "As a result of these 
studies we no longer hear shrill voices proclaiming that schizophrenia arises from toxic interpersonal family environments.”

Others point to the influence of work in the 1960s on neurotransmitters, especially animal research showing that the newly discovered drug Thorazine (which helped the symptoms of schizophrenia) depleted available dopamine levels in laboratory animals. This work led some to suggest that schizophrenia was a disorder caused by an excess of dopamine in the brain, a perspective which certainly helped to bolster the case for seeing medication as a front-line treatment for the disorder. And still others point to new brain imaging work at this time that seemed to identify such things as enlarged brain ventricles as a reliable marker distinguishing the schizophrenic from the normal brain.

These research developments and new pharmaceutical options emphatically mattered. They were important. But, on their own, they were not decisive. We can say this with some assurance because right through the late 1980s, the question as to whether schizophrenia was essentially a psychogenic or a biological disorder was still considered unsettled in most clinical circles. Indeed, until the late 1980s and even early 1990s, many textbooks and medical school courses still gave the biological perspective short shrift, while giving serious attention to theories of deficient maternal nurture. Remember that, for decades, there had a continuing stream of research purporting to advance the case for an organic or brain-based theory of schizophrenia. Little of this work had ever been deemed decisive or enduring; and it was not immediately clear to people not already persuaded of the biological theory of schizophrenia that the new work of Seymour Kety and others was enough to tip the balance. 
What did tip the balance? Part of the answer, but only part, is a shifting cultural environment marked by a new moral distaste of the most derogatory and punitive forms of mother-blaming which had proliferated in the 1950s and 1960s. As Betty Friedan noted in her 1963 Feminine Mystique: "Under the Freudian microscope... it was suddenly discovered that the mother could be blamed for almost anything. In every case history of a troubled child...could be found a mother." By 1970, a group of radical women psychotherapists who called themselves the San Francisco Redstockings had begin distributing literature to sympathetic colleagues at the American Psychiatric Association, which included the following suggestion: "Mother is not public enemy number one. Start looking for the real enemy."

Alongside the pamphleteering of activist groups like the Redstockings, a small but growing number of articles and books by feminist psychologists like Phyllis Chesler also helped to stoke skepticism about the mother-blaming game. Chesler's 1972 work on women, madness and psychiatry seem to have been one of the first feminist critiques of the theory of the schizophrenogenic mother. Tellingly, however, the book only challenged the ethical and not the intellectual grounds for that theory, and it certainly did not suggest that schizophrenia was best conceived as a brain disorder. On the contrary, Chesler accepted that mothers of schizophrenic patients were responsible for their children's mental illness. However, she suggested that they should not be blamed for the damage they caused because, in an oppressive patriarchal society, they were almost certainly as psychologically damaged as their children - and so could not help themselves. "Perhaps the mothers are as hospitalized within their marriages as their daughters are within the asylums..."

Close readings of the relevant texts themselves thus makes clear that feminism too falls 
short as an explanation on its own for the way in which, over the course of the 1980s, schizophrenia ceased to be a disorder of maternal failure and became a disorder of faulty brain functioning. What missing element then is needed to finally explain this development? The answer is: deinstitutionalization - and, ironically enough, a certain kind of ferocious, politicized (and not uncontroversial) mother love that would be catalyzed by it.

Deinstitutionalization was the radical social experiment (and economic strategy) of the 1960s and 1970s that involved releasing enormous numbers of patients from state mental hospitals, including chronically psychotic patients. The reasoning was that, properly medicated (since new drugs had become available in the mid-1950s), these patients could now live and be treated in the community. This would be much better than spending their lives in a dismal public mental hospital, cut off from society. It would also be much cheaper for the states (no small fact), which could now hope that their chronic mentally ill wards would be cared for in federallyfunded community health centers.

Things, of course, turned out to be more complicated than that. Once released, many patients went off their medications, did not refill their prescriptions, and either lacked access to a community center (many failed to be built) or failed to show up for appointments at one to which they had been assigned. Instead, many cycled in and out of emergency rooms, became homeless, and/or ended up in prison. The lucky ones, though, had parents who tried to step into the breech and figure out what it might mean, really, to care for severely mentally ill people "in the community." These parents found themselves in crisis as they tried to navigate a mental health care system that no longer seemed to have resources for their children. 
By a rather cruel irony, however, many of these family caregivers were precisely the same people who had previously been blamed and censured for their inadequate parenting by the hospitals and experts to whom they hard turned. Now they had been left without resources and guidance, and some of them began meeting to discuss their sense of frustration and anger. They discovered and built alliances with the biological wing of psychiatry, which told them that schizophrenia was a disease like any other, and no one's fault, least of all theirs. They lobbied congress for more funding for biological research, and even gave grants of their own. There was a lot of love and fear driving the organization of these parent groups. As one mother said "We are worried about what will happen to our children after we die."

In 1973, one of these mothers, Eve Oliphant, founded Parents of Adult Schizophrenics (PAS) in San Meto County, California. By 1978, PAS included 200 family groups and had become increasingly activist in its orientation. In 1979, Beverly Young and Harriet Shetler, two mothers, thus proposed creating a national alliance for the mentally ill. In September 1979, a hundred such groups came together to form the National Alliance for the Mentally Ill. (NAMI). Less than four years later, the National Alliance had nearly 250 affiliates.

For our purposes, the most important fact to know about NAMI is that its platform explicitly rejected all the theories of the time which "implicate parents in the genesis or aggravation of mental illness." Its goal instead was to use its growing influence to advocate for more research into the biological roots of schizophrenia, better (pharmaceutical) treatment for patients, and better accountability from the psychiatric leadership which had misled and hurt so many parents. In the words of one of these parents, spoken before a large crowd of clinicians at 
the World Congress on Psychiatry in 1977: "We failed to understand why parents of a child with leukemia were treated with sympathy and understanding, while parents of a child with

schizophrenia were treated with scorn and condemnation.”

A few years later, in 1981, social workers Carol Anderson and Gerard Hogarty published impressive outcome findings for a new approach to family therapy in schizophrenia: something they called psychoeducation. In sharp contrast to the dominant family therapy approaches of the time, this new therapy concentrated, not on seeing families as the cause of their children's illness, but on building emotional alliances with them. It turned out that, when families were approached sympathetically and taught skills for coping better with the profound emotional and interpersonal challenges of being the front-line caregivers of a schizophrenic child, there was a significant reduction in the relapse rates of the children themselves. There might or might not be any scientific evidence to support the idea that families could cause schizophrenia (and, in fact, Anderson and Hogarty were skeptics of this idea). What was clear, though, was that blaming as a practical approach - especially in the 1980 s, a time when so many more families were directly involved in the care of such patients -- did not work.

By the first half of the 1980s, previously more marginalized biological perspectives on schizophrenia were beginning to attract more attention. At the same time -- and in concert with this development - it became apparent that a major transformation in the attitude of mental health clinicians towards families was in process. 1982 saw the publication of the first handbook, written by biological psychiatrist E. Fuller Torrey, which was designed specifically to help, not patients, but their families "survive" schizophrenia. One particularly striking cultural marker of 
the sea change can be seen in a 1984 television documentary that aired on public television in the United States -- part of a five-part series on the brain. Called simply "Madness" it was devoted to the then still novel idea that schizophrenia was a brain disease. The hour-long show included scenes that showed psychiatrists - including E. Fuller Torrey -- interacting with severely incapacitated schizophrenic patients, and interviews with sympathetic mothers involved in the founding of NAMI. Above all, the documentary functioned as a kind of extended public apology to parents. Once upon a time, the clinicians on the television said, psychiatry was inclined to hold parents responsible for their children's illness, but there was not a "shred of evidence" in support of this idea. On the contrary, parents were as much innocent victims of a terrible biological disorder as their children. In the words of one of the psychiatrists interviewed in this documentary: "They are like people who have been struck by lightning."

In 1986 an article appeared in small regional newspaper, the Oelwein Registe, entitled, significantly, "Every family's Story." It told the tale of an unnamed generic family, one that any reader might identify with, who found themselves dealing with a bewildering tragedy. Their teenage son, suddenly and without any obvious cause, was losing touch with reality, believing he was being persecuted by witches but that he had paranormal powers to resist them.

They could not believe that this was happening to Mike...to them. Their kid wasn't really — the word did not come easily—really...crazy. Craziness was something that happened to other people, to awful people, to families that were abnormal, to families that treated their kids badly. It couldn't happen to them. Except that it was happening to them, in a nightmare they couldn't wake up from. Maybe they had made a mistake in thinking he 
was mentally ill. After all, who among them knew anything at all about such things. They reconsidered the evidence. Was Mike really crazy? There was no getting around it. He was.

The story closed with the frightened mother calling the police on her own dearly-loved son after he became violent towards another child. The young man (who had up to this point resisted all efforts to get him to see a psychiatrist) was taken away to a mental hospital in hand cuffs. "And so," the article concluded, "Everyfamily met schizophrenia." By 1986, the message was clear: schizophrenia was a devastating brain disorder that could strike the most loving of families. The only course available to a loving mother in such a situation was to use any means possible to ensure that a child got the medical help he or she needed, even if that meant involuntary commitment.

\section{Conclusion}

The story of the mother who literally drove her offspring crazy was the radical, ragged edge of a larger history that entailed, first a medicalization and then a politicization of mother love. The larger story began with psychiatry validating mother love as critical to the healthy development of children; it moved to a focus on ways in which unhealthy forms of mother love might thwart the development of troubled youngsters; and then it moved again, to increasingly shrill claims about ways in which unhealthy forms of mother love put democracy itself at risk.

In the case of the specific story of mother love and mental illness, however, something novel happened: a new politicization of mother love; but this time, one transformed into a 
movement that would compel psychiatry to own up to its ineptitude, force a reorientation of the field back to its biological roots, and catalyze a crisis of conscience over its former casual cruelty towards suffering families. On its own terms, this final politicization of mother love was an astonishingly successful strategy. By the 1990s, psychoanalytically-oriented clinicians who once were seen by their peers as serving the cause of love (for their patients) had been transformed by new critics into misogynists who, wittingly or not, had sown hatred (of parents). Apologies were made. Fervent desires for a new beginning were affirmed.

To be sure, none of this meant that blame and guilt vanished from the world of schizophrenia entirely. The biologization of schizophrenia brought its own kind of guilt, as parents now wrestled with the idea that a genetic vulnerability towards schizophrenia ran through their family line. Nevertheless, the fact remains that in our own time even the most moderate psychosocial approaches to schizophrenia have become, in the eyes of many, not just scientifically wrong, but positively unethical. Most people take for granted that the gold-plated solution to both the suffering and the stigma of schizophrenia is more and better research into its neurobiological basis, and more and better drugs. They fail to realize, however, that the genetics and brain science which provided the original intellectual justification for a turn back to a strict biological approach to schizophrenia was always, at best, provisional and incomplete. There was always more to be said and done. As anthropologist Tanya Luhrmann has put the matter in a recent (2012) article:

In the early days of the biomedical revolution, when schizophrenia epitomized the pure brain disorder, the illness was said to appear at the same rate around the globe, as if true 
brain disease respected no social boundaries and was found in all nations, classes, and races in equal measure. This piece of dogma was repeated with remarkable confidence from textbook to textbook, driven by the fervent anti-psychoanalytic insistence that the mother was not to blame. No one should ever have believed it. As the epidemiologist John McGrath dryly remarked, 'While the notion that schizophrenia respects human rights is vaguely ennobling, it is also frankly bizarre." In recent years, epidemiologists have been able to demonstrate that while schizophrenia is rare everywhere, it is much more common in some settings than in others, and in some societies the disorder seems more severe and unyielding. Moreover, when you look at the differences, it is hard not to draw the conclusion that there is something deeply social at work behind them.

We should not have to choose between biological and social understandings. It should be axiomatic that all human beings, even those with biological vulnerabilities that put them at risk of schizophrenia, are embedded in a social and interpersonal world that gets under their skin and affects them. By and large, though, people fail to see this, and they fail to see this in part because of legacies from the history just recounted here. On the one side, psychiatry's engagement with mother love is a profoundly important chapter in the $20^{\text {th }}$-century history of the medicalization of emotions. On the other side, it is also an emotionally-fraught history in its own right, which still stirs strong passions. Understanding this fact, and its consequences, may be one important way in which, for the sake of science, patients and families, psychiatry and its clients alike can begin to recover from the trauma of a recent fraught and antagonistic past. 
